\title{
Uma tragicomédia que dialoga com Samuel Beckett
}

\author{
Maria Helena Serôdio
}

\section{EM BAIXO E EM CIMA A PROPÓSITO DE BECKETT \\ JORGE GOMES RIBEIRO}
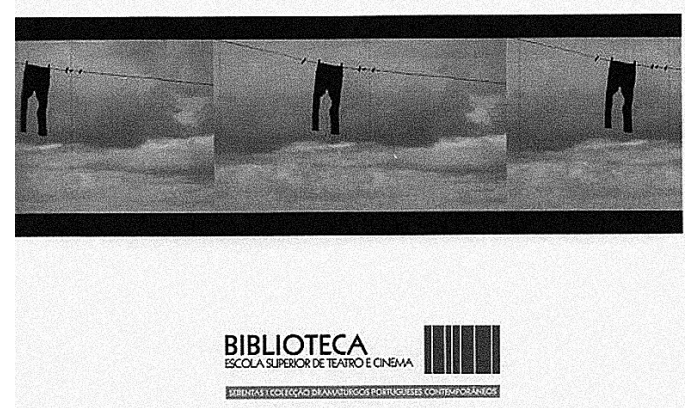

Jorge Gomes Ribeiro, Em baixo e em cima: A propósito de Beckett, Prefácio de Carlos J. Pessoa, Amadora, Escola Superior de Teatro e Cinema, 2014, 57 pp.

Visando preparar uma dissertação de Mestrado no âmbito dos Estudos de Teatro - da Faculdade de Letras da Universidade de Lisboa -, Jorge Gomes Ribeiro (JGR) escolheu a peça $\dot{A}$ espera de Godot, de Samuel Beckett, como ponto de partida para uma investigação teórica e crítica em torno do teatro do absurdo. Centrou a sua leitura e reflexão no que designou como "marcadores de encenação" na dramaturgia beckettiana, referindo-se, assim, a uma forma especifica de pensar a relação entre texto e cena.

Todavia, esse exercício de reflexão crítica sobre a dramaturgia de Beckett acabou por induzir JGR não apenas à definição de algumas linhas de leitura desse teatro, mas também a uma hipótese criativa em experimentação dramatúrgica: a escrita de uma peça - Em baixo e em cima: A propósito de Beckett - como proposta de possivel reenunciação hoje da problemática do absurdo.
Esse texto surgia, portanto, na sua dissertação como um Apêndice, propondo-se como verificação produtiva de um outro modo de dialogar com o texto beckettiano.

Foi agora publicado esse texto em volume ${ }^{1}$, integrando um curto prefácio de Carlos J. Pessoa, no qual o professor, dramaturgo e encenador recorda a frequência, por JGR, de seminários de Encenação, que ele dirigia na Escola Superior de Teatro e Cinema (ESTC), e no âmbito dos quais o processo criativo de JGR se desenvolveu, vindo a peça - então escrita - a ter estreia cénica na sala de teatro dessa instituição de ensino.

Talvez possamos dizer que o texto, que agora se publica, cumpre dois desejos do seu autor: por um lado, o de dialogar com Samuel Beckett, ou melhor, com o "pequeno deus" (= Godot) de Beckett; por outro, dar conta do que foi o processo laboratorial que decorreu no âmbito desses dois seminários de Encenação.

No diálogo implícito com À espera de Godot - alargado, porém, a outros textos de Beckett -, JGR mantém um visivel paralelismo de composição dramatúrgica que, apesar de se reconduzir a um só acto, não deixa de apresentar convergências significativas em oito pontos principais:

1. Dois homens conversam entre si, e há nesse diálogo de frases curtas e paralelas - a "revisão" de histórias e cenas mais ou menos efabuladas, mas também a ideia de um interessante jogo de ping-pong verbal em sequência delirante:

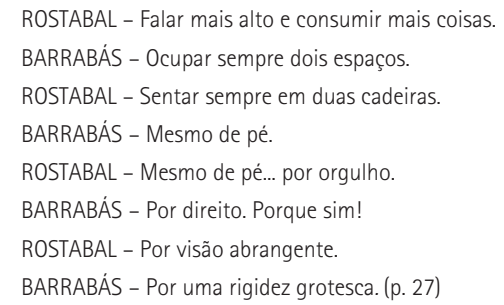

2. 0 espaço a sugerir em cena é relativamente incaracteristico pelo seu traço de esvaziamento e sem limites à esquerda e à direita, tendo apenas um simples adereço que confere um expressivo ponto de apoio aos actores e acrescenta um sentido dramatúrgico: se em Beckett é uma estrada numa paisagem mais ou menos deserta onde há uma árvore; aqui é a sugestão de um beco, mal iluminado, onde está uma mala de porão (um baú de pequenas dimensões) a que se juntará a certa altura um saco cheio de latas vazias;

\section{${ }^{1} 0$ volume, apesar de um tamanho simpático, uma capa muito interessante e uma paginação de grande legibilidade, apresenta algumas} gralhas - em acentos, bem como na grafia de algumas palavras ou no espaçamento entre elas que talvez justifiquem uma segunda edição, até porque a qualidade do texto acordará, com toda a certeza, o interesse de leitores pela sua aquisição. 
3. No texto de JGR há uma acção mínima, em torno de um baralho de cartas: prossegue, assim, de algum modo uma espécie de jogo que nos aparece nalguns textos de Beckett, embora no autor irlandês seja talvez o xadrez a opção mais presente (em Murphy);

4. Não há, todavia, na peça de Jorge Gomes Ribeiro, um par como o de Pozzo e Lucky a irromper pela cena, mas há a referência a um outro lugar - um eventual reformatório "dos garotos abandonados, das cabeças rapadas, o reformatório dos suicidas" - de onde surge um rapaz, o Boinas, que terá fugido e que mais tarde aparecerà em cena sentado numa cadeira de rodas (curiosamente com rodas de bicicleta...);

5. A esse rapaz prende-se depois uma "história" que Rostabal conta: a de ter percebido no rapaz do reformatório uma situação de desamparo e um imenso desejo de montar na bicicleta: por isso lhe emprestou a sua bicicleta, para grande espanto e alegria do rapaz, que, todavia, posteriormente se "esqueceu" de a devolver;

6. Fala-se, portanto, de andar numa bicicleta e este é um tropismo relativamente conhecido da prosa beckettiana como, de resto, ocorre em More Pricks than Kicks e em Molloy, para já não falar de uma outra recordação - de um passeio de bicicleta - que teve, porém, um fim desastroso: Nagg e Nell (de Fim de partida) que perdem as pernas, ao passear de tandem nas Ardenas. Ganha aqui, no texto de JGR, uma coloração específica: a ideia de fuga no selim de uma bicicleta;

7. Mas a questão maior da conversa entre Rostabal e Barrabás versará sobre as limitações do corpo (modo de andar desengonçado...) e de como, ao saltar o muro, o rapaz partiu os dois tornozelos e a bacia;

8. 0 pedido, por Barrabás, de um rebuçado - tantas vezes reiterado - confunde-se também com a necessidade de um testemunho da amizade, o conforto de um gesto de afecto; mas a verdade é que Rostabal só tem maçãs para Ihe dar e mesmo essas, pelo menos algumas, não estão boas para comer...

Outros temas beckettianos surgem ainda no texto do JGR: a conversa sobre Jesus que encontramos em Watt, Molloy, O calmante, Comment c'est, À espera de Godot (lembremo-nos de que aqui, nesta peça, se fala de "uma percentagem honesta" entre a salvação e a perdição a propósito dos dois ladrões crucificados juntamente com Jesus Cristo). Essa referência a Jesus ganha no texto do JGR uma ressonância muito próxima de nós e interessante ao desembocar por vezes na pequena lógica de algibeira que parece habitar hoje o lugar comum das conversas de café: a necessidade da formação de "grupos de discussão" para eleger o que seria mais premente: se procurar uma "direcção" ou privilegiar um "percurso" naquilo que poderia ser a relação a instituir entre cada um e Jesus, por exemplo..

Dessas tais conversas derivam enunciados formalmente lógicos que servem, todavia, para acentuar o absurdo das conclusões (parodiando, aliás, no final, uma certa deriva mercantilista), ou simplesmente para declarar "que o rei vai nu". Assim lemos no texto de JGR a certa altura:

BARRABÁS - [...] houve um outro que disse que para se fazer um percurso o melhor era comprar sapatos como os do Jesus, porque descalços como estavam, ninguém ia a lado nenhum. Então as pessoas desataram a comprar sapatos para ter o percurso que o Jesus tinha tido. (p. 24)

Na atenção - só aparentemente - distraída relativamente ao real, há, todavia, lugar para verificações exactas que surgem, porém, contaminadas por um acento joco-sério:

BARRABÁS - [...] A um dado momento as pessoas andavam todas de casacos iguais, aos magotes, e movimentavam-se de um lado para o outro num impeto arrasador. Inexplicavelmente ninguém tinha aprendido a ler.

ROSTABAL - Ora ai está uma situação cheia de perspectivas animadoras! (p. 24)

No meio destas altercações - de sentido mais irónico que sarcástico -, há de repente no texto do JGR uma "fuga para cima" (literalmente):

BARRABÁS - [...] Eu comecei a sair dali para evitar a confusão e algumas perguntas. Perguntavam-me se eu já tinha uma direção ou se estava nalgum percurso e eu como não tinha uma coisa nem outra e não estava nada interessado, habituei-me a ir olhar para as estrelas. (/bid.)

Vemos, de facto, no texto do JGR um exercício especular na sua relação com Beckett, acompanhando alguns dos seus traços maiores: um certo tom filosofante que se entretece com o lugar comum, e o absurdo que se alia a um inesperado sopro lírico.

Por exemplo, ao fugir do Reformatório, o Boinas acompanha algumas das personagens beckettianas que parecem chutadas para a rua - ou para o mundo no seu sentido mais amplo. E essa é uma micronarrativa curiosa enunciada entre o registo descritivo e o assomo do inesperado (pela falta de lógica):

BOINAS - Firmei os cotovelos no passeio e por momentos passou pela minha cabeça um vislumbre desta minha nova liberdade. Fui arrancado a este devaneio pelo barulho da minha boina que rodopiando aterrou com estrondo ao meu lado. Curiosa recordação 

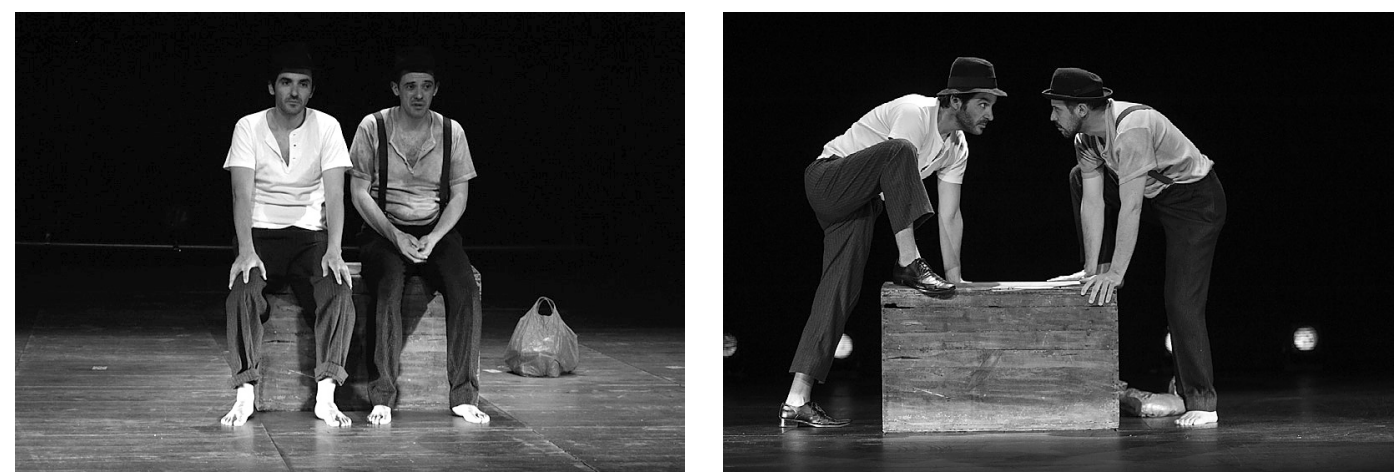

$<>v$

Em baixo e em cima:

A propósito de Beckett, de e enc. Jorge Gomes Ribeiro, Escola Superior de Teatro e Cinema, 2013 (<> Sérgio Moura Afonso e Sérgio Moras $\checkmark$ Ruy Malheiro, com Sérgio Moura Afonso e Sérgio Moras ao fundo), fot. Rita Fernandes.

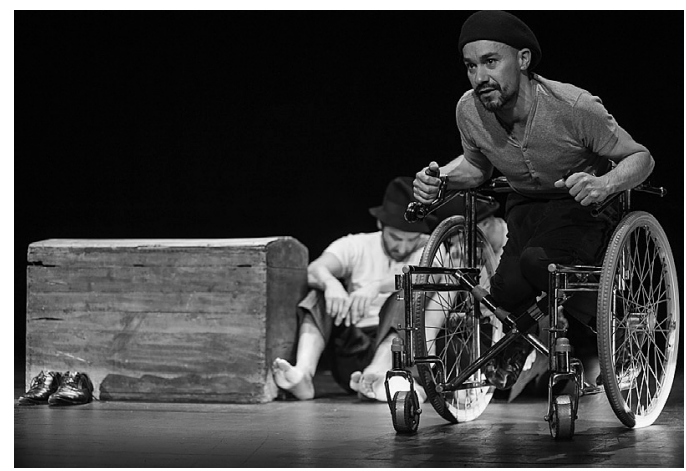

esta de a boina ter ficado para trás, eles podiam ter ficado com ela. Agarrei-a e enfiei-a na cabeça. (pp. 49-50)

Essa deriva fantasiosa não deixa de sugerir, afinal, uma imaginação em rédea solta. A que não falta, porém, um sentido de compaixão pelos outros, como o tópico do reformatório traz à conversa.

A isto se juntam ainda dois tipos de construção frásica que não podem deixar de revelar uma ironia especial:

1. A acumulação rebarbativa de lugares comuns, como a justificar um saber inquestionável, mas que se apresenta com a marca de uma platitude universal:

\section{ROSTABAL - Cada um é o que é! \\ BARRABÁS - Cada um é como cada qual! \\ ROSTABAL - 0 esencial nunca se altera. \\ BARRABÁS - Cada um sabe de si. (p. 14)}

2. Ou então o nonsense a engendrar frases em que a primeira parte da frase nada tem - logicamente - a ver com a segunda parte:

\section{ROSTABAL - Ouvir menos e ter os ombros mais largos. (p. 27) [...] \\ ROSTABAL - Falar mais alto e consumir mais coisas. (lbid.)}

Ao lado destas derivas algo sonâmbulas, alguns dos diagnósticos sobre o mundo, em que vamos vivendo, são de uma coloração mais de humor negro, mas não desprovido de uma violenta verdade na aproximação a alguns comportamentos desalmados:

BARRABÁS - Estás a falar de quê, vamos lá a morrer, morrer depressinha, como na vida, morrer enquanto é tempo, morrer enquanto há vida. (p. 47)
Ou então, sobre a obsessão das contabilidades, a pura linguagem dos números, mas que não prescinde do "grande referente":

\section{BARRABÁS - Mentiras, mentiras vestidas de verdades. Nada de sonhos, apenas factos. Especialistas de uma verdade contabilistica. Apenas factos. Eis o coro dos contabilistas, os contabilistas opinam, como um só homem, com uma só conta, com uma só contabilidade. BOINAS - É uma contabilidade de biliões [... ] \\ BARRABÁS - Biliões em cima de biliões. Todos em fila, \\ contabilisticamente em fila... \\ BOINAS - (Um tempo.) E no fim teria de haver um Deus. Uma testemunha da contabilidade. (pp. 48 e 49 )}

E, ainda, uma curiosa tendência para declarações genéricas sobre o comportamento humano em que a apreciação crítica surge travestida de um sentido de denegação:

BARRABÁS - Ninguém ouve ninguém.

ROSTABAL - É uma actividade aos pares. (p. 33)

0 sentido de uma humanidade à deriva - de que dá conta o texto de JGR - recupera, por isso, algumas frases de Beckett, recapitulando as que se tornaram ícones verbais da sua escrita, como a da enunciação do falhanço universal:

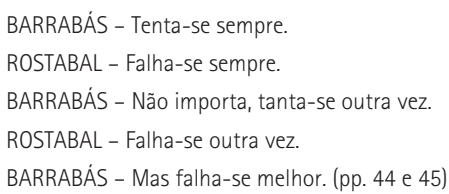

Ainda que usando uma organização discursiva que parece presidir à reflexão filosófica em sentido geral, o jogo dialógico opera no sentido de dessorar qualquer pronunciamento, jogando na ironia e derrisão, e declarando, assim, a impossibilidade de uma efectiva redenção.

A peça de JGR torna-se, assim, um exercício - curioso, inspirado - que, falando de Beckett, institui um diálogo vivo com a sua obra, a partir, todavia, de uma instância que também fala do aqui e do agora: com ironia e alguma compaixão.

Comprova, deste modo, não apenas a sua compreensão do mundo beckettiano, mas também a capacidade de reelaborar um jogo teatral em que experimenta - com agilidade discursiva e operatividade cénica - uma hipótese dramatúrgica: pôr esse mundo a falar a língua portuguesa e a circunstância nossa, de hoje e aqui em $2014 .$. 